\title{
Congruent and Incongruent Corticospinal Activations at the Level of Multiple Effectors
}

\author{
Luisa Sartori $^{1}$, Sonia Betti ${ }^{1}$, Chiara Perrone ${ }^{1}$, and Umberto Castiello ${ }^{1,2}$
}

\begin{abstract}
Motor resonance is defined as the subliminal activation of the motor system while observing actions performed by others. However, resonating with another person's actions is not always an appropriate response: In real life, people do not just imitate but rather respond in a suitable fashion. A growing body of neurophysiologic studies has demonstrated that motor resonance can be overridden by complementary motor responses (such as preparing a precision grip on a small object when seeing an open hand in sign of request). In this study, we investigated the relationship between congruent and incongruent corticospinal activations at the level of multiple effectors. The modulation of motor evoked potentials evoked by single-pulse TMS over the motor cortex was assessed in upper and lower limb muscles of participants observing a soccer player performing a
\end{abstract}

\section{INTRODUCTION}

Findings supporting the hypothesis that there is a basic neurophysiologic system underlying the ability in an onlooker's brain to match another person's body movements with our own motor representations have been drawn from different methodological approaches. Single cell recordings demonstrated the existence of "mirror neurons," which discharged both when a monkey actually grasped 3-D objects and when it observed that action being carried out (Gallese, Fadiga, Fogassi, \& Rizzolatti, 1996; Di Pellegrino, Fadiga, Fogassi, Gallese, \& Rizzolatti, 1992). In humans, single-neuron responses were likewise recorded during both action execution and observation (Mukamel, Ekstrom, Kaplan, Iacoboni, \& Fried, 2010), and neuroimaging studies provided evidence that the fronto-parietal system is implicated in coupling the representations of executed and observed actions (for a review, see Molenberghs, Cunnington, \& Mattingley, 2012; Turella, Tubaldi, Erb, Grodd, \& Castiello, 2012; Keysers, 2009; Fabbri-Destro \& Rizzolatti, 2008; Giorello \& Sinigaglia, 2007; Rizzolatti \& Craighero, 2004). Motor resonance is defined as the subliminal modulation of motor pathways, which reproduces in whole or in part the activation normally utilized to execute the observed ac-

${ }^{1}$ Università di Padova, ${ }^{2}$ Accademia Nazionale dei Lincei, Rome, Italy

(C) 2015 Massachusetts Institute of Technology penalty kick straight in their direction. Study results revealed a double dissociation: Seeing the soccer player kicking the ball triggered a motor resonance in the observer's lower limb, whereas the upper limb response afforded by the object was overridden. On the other hand, seeing the ball approaching the observers elicited a complementary motor activation in upper limbs while motor resonance in lower limbs disappeared. Control conditions showing lateral kicks, mimicked kicks, and a ball in penalty area were also included to test the motor coding of object affordances. Results point to a modulation of motor responses in different limbs over the course of action and in function of their relevance in different contexts. We contend that ecologically valid paradigms are now needed to shed light on the motor system functioning in complex forms of interaction.

tions. In particular, a growing body of neurophysiologic studies have demonstrated that action observation selectively activates the effector muscles involved in performing that action (for a review, see Fadiga, Craighero, \& Olivier, 2005). The motor potentials (MEPs) evoked by TMS during action observation appear, in fact, to be specifically attuned to the muscles involved in the action being observed (Sartori, Bucchioni, \& Castiello, 2012; Alaerts, Heremans, Swinnen, \& Wenderoth, 2009; Avenanti, Bolognini, Malavita, \& Aglioti, 2007; Urgesi, Candidi, Fabbro, Romani, \& Aglioti, 2006; Strafella \& Paus, 2000; Fadiga, Fogassi, Pavesi, \& Rizzolatti, 1995) and to its temporal pattern (Janssen, Steenbergen, \& Carson, 2013; Urgesi et al., 2010; Aglioti, Cesari, Romani, \& Urgesi, 2008; Borroni \& Baldissera, 2008; Borroni, Montagna, Cerri, \& Baldissera, 2005; Montagna, Cerri, Borroni, \& Baldissera, 2005; Kilner, Vargas, Duval, Blakemore, \& Sirigu, 2004; Gangitano, Mottaghy, \& Pascual-Leone, 2001).

However, in human social interactions, resonating with another person's action is not always an appropriate reaction (e.g., Hamilton, 2013; Knoblich, Butterfill, \& Sebanz, 2011; Sebanz, Bekkering, \& Knoblich, 2006). For instance, when we observe someone handing us a mug holding it by its handle, we will, without thinking, grab the mug with a whole-hand grasp (the most appropriate gesture to perform in this situation, although different from that observed). Along these lines, a growing amount of evidence 
highlights the interplay between the inflexible tendency to match observed actions onto our motor system and the request to prepare complementary responses with respect to the observed actions (Ocampo, Kritikos, \& Cunnington, 2011; Sartori, Cavallo, Bucchioni, \& Castiello, 2011; Flach, Press, Badet, \& Heyes, 2010; Ocampo \& Kritikos, 2010; Sartori, Becchio, Bulgheroni, \& Castiello, 2009; van Schie, van Waterschoot, \& Bekkering, 2008; Newman-Norlund, Noordzij, Meulenbroek, \& Bekkering, 2007). In a series of recent psychophysiological studies, researchers assessed corticospinal (CS) facilitation while participants observed video clips evoking complementary gestures, such as an actor inviting them to pick up a cup placed in the video foreground (Sartori, Betti, \& Castiello, 2013a, 2013b; Sartori, Bucchioni, \& Castiello, 2013; Sartori, Cavallo, Bucchioni, \& Castiello, 2012). Consistent results showed a natural switch from a motor resonant to a complementary activation in CS excitability.

Capitalizing on this literature, here, we asked participants to observe meaningful action sequences, and we avoided imparting instructions to uncover spontaneous congruent and incongruent CS modulations in different limb muscles. In particular, we adopted a paradigm involving videos of penalty kicks in view of the well-established association between observing someone in frontal view kicking a ball far above the ground-straight in our direction - and the spontaneous reaction (i.e., parrying the ball). The effectiveness of this manipulation in priming an upper limb reaction has been confirmed in different studies (Sartori, Betti, Chinellato, \& Castiello, 2015; Tomeo, Cesari, Aglioti, \& Urgesi, 2013). We thus filmed penalty kicks performed by a soccer player who ran up to a ball and then kicked it straight in the direction of the goal-the place from which the action was filmed and thus the perspective of the person who was watching the video clip (Figure 1A).

Three additional control conditions were also included: Participants were asked to observe the video of a penalty kick that was not directed toward them (Figure 1B) and another kick that was only mimicked, without the ball (Figure 1C). Finally, the image of a soccer ball was shown alone in the penalty area (Figure 1D) to control for the motor coding of object affordances (Tucker \& Ellis, 1998; Gibson, 1979). It is well known, indeed, that visual information linked to an object is transformed into appropriate motor commands even in the absence of an explicit intention to act (Craighero, Fadiga, Rizzolatti, \& Umiltà, 1998; Tucker \& Ellis, 1998; Jeannerod, 1994). Crucially, soccer balls offer a unique control for our purposes in that they elicit both hand and leg muscles (i.e., contrary to basketballs or baseballs, we not only use our hands for throwins but also kick them).

Single-pulse TMS was used to assess CS excitability of participants' hand and leg muscles as they watched the videos. Because participants remained at rest throughout the task, the degree to which the motor system was activated provides an index of activity elicited by action observation.

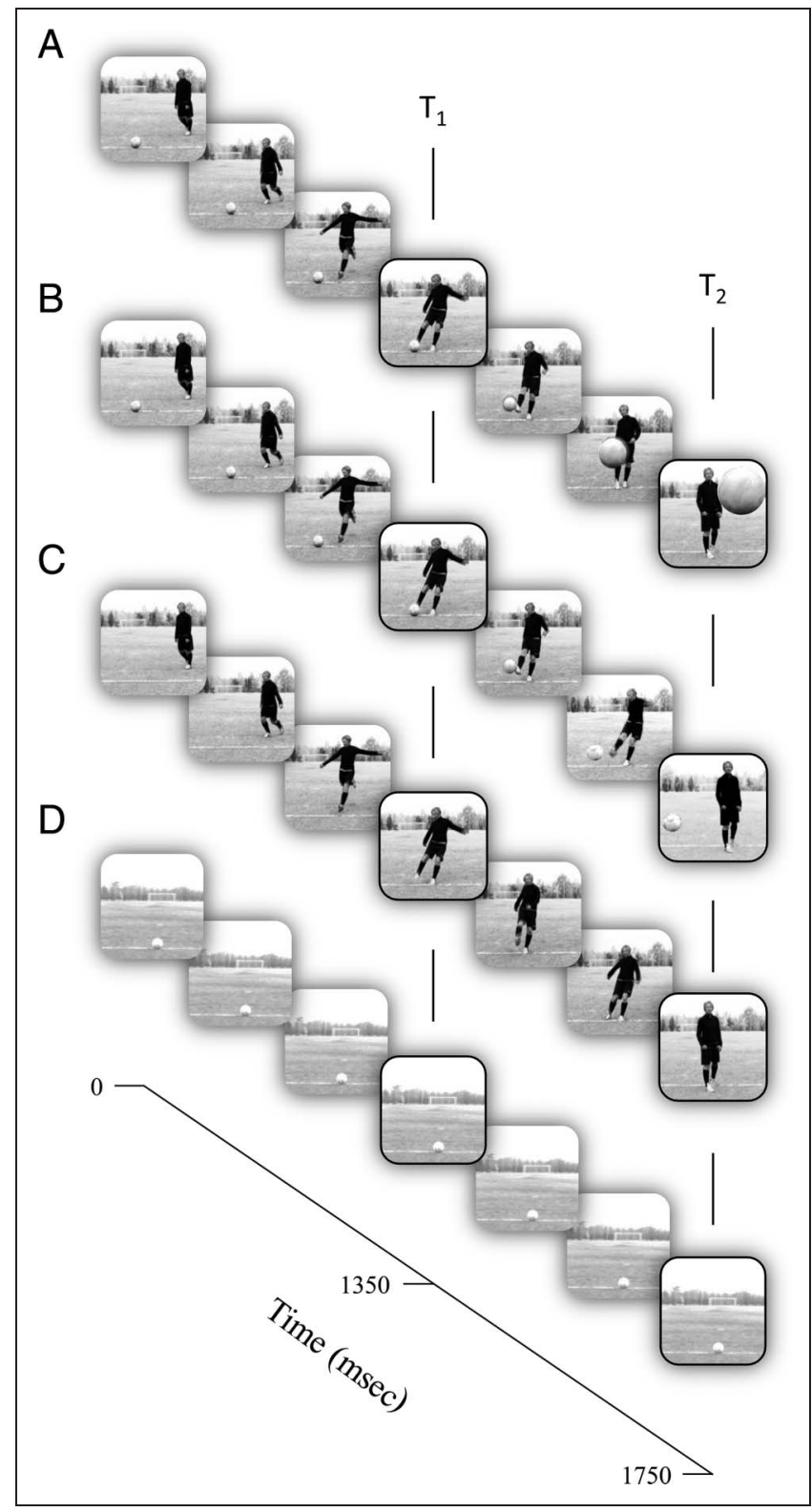

Figure 1. Sequence of events for each condition: (A) Central kick, (B) lateral kick, (C) mimicked kick, and (D) ball. The vertical lines denote the time points when single TMS pulses were delivered: at $T_{1}$ (when the player's foot made contact with the ball) and at $\mathrm{T}_{2}$ (the end of the video clip).

We hypothesize that facing a central penalty kick might prime a complementary motor activation, depending on the action progression. In particular, we expected a motor resonant response in participants' leg muscles during the first part of the video showing a soccer player running and kicking the ball, along with the suppression of upper limb motor responses afforded by the object, and vice versa during the second part of the video. An activation in participants' upper limb muscles was expected along with the suppression of lower limb muscles. We also predict that presenting a simple mimicked kick without the ball would only produce motor resonance in lower limbs, whereas observing a ball in the penalty area should 
elicit activation in both limbs because of the motor coding of object affordance. To better control for affordance effects linked to the ball, we included a lateral kick condition, in which the ball was shown disappearing to the left after the kick. We expected that this action would produce motor resonance in the observers' lower limbs, associated with the suppression of upper limb responses. We specifically selected an extensor leg muscle and an abductor hand muscle to rigorously test our predictions because they are typically recruited during kick and parry actions. This allowed us to avoid possible alternative explanations in terms of generalized unspecific activations.

\section{METHODS}

\section{Participants}

Thirty individuals (19 women; $M_{\text {age }}=23$ years, $S D=$ 2 years) participated in the experiment. All the participants were right-handed (Briggs \& Nebes, 1975), reported rightfoot dominance, and had normal or corrected-to-normal visual acuity. As their greater action simulation abilities could have biased the results, individuals with any motor expertise in playing soccer were excluded from the experiment by means of a prescreening procedure. Athletes, in fact, present superior abilities in predicting and anticipating other players' actions (Makris \& Urgesi, 2014; Tomeo et al., 2013; Urgesi, Savonitto, Fabbro, \& Aglioti, 2012; Abernethy, Zawi, \& Jackson, 2008; Aglioti et al., 2008; Weissensteiner, Abernethy, Farrow, \& Müller, 2008). Notably, observational practice may contribute to action prediction abilities (Urgesi et al., 2012), and soccer is a quite familiar sport. However, in this case, we presented an action sequence observed from the goal post, and this is quite an uncommon view. None of the participants had any neurological, psychiatric, or other medical problems, nor did they have any contraindication to TMS (Rossi, Hallett, Rossini, Pascual-Leone, \& Safety of TMS Consensus Group, 2009; Wassermann, 1998). None was aware of the experiment's purpose, and all gave their written informed consent at the time they were recruited. The study protocol was approved by the ethics committee of the University of Padova and was carried out in accordance with the principles of the Declaration of Helsinki. None of the participants reported experiencing discomfort or adverse effects during the experiment.

\section{Stimuli}

The stimuli were four digitally recorded video clips showing penalty kicks by a professional soccer player (Figure 1A-D): (a) In the first, the player kicked the ball into the goal straight toward the observer; (b) in the second, the player kicked the ball clearly to the left of the camera; (c) in the third, the player mimicked kicking a ball; and (d) in the fourth and last, a static soccer ball was shown. All of the videos were taken from a frontal view. A 1800-msec sequence was extracted from each of the four videos, which included the player's initial run and the ball's trajectory until it disappeared. The player's foot made contact with the ball approximately $1350 \mathrm{msec}$ after the video began, and the ball trajectory reached its highest peak approximately $400 \mathrm{msec}$ later (1750 msec after onset of the video). The ball was traveling at a velocity of approximately $10 \mathrm{~m} / \mathrm{sec}$ during its trajectory. An animation effect was obtained by presenting a series of single frames each lasting $25 \mathrm{msec}$ (resolution $=720 \times$ 576 pixels, color depth $=24$ bits, frame rate $=30 \mathrm{fps}$ ) after the first frame, which lasted $500 \mathrm{msec}$. A preliminary pilot investigation, carried out with a questionnaire and the assistance of a group of participants with characteristics that were similar to those participating in the study experiment, confirmed that only the central kick (straight toward the observer) led in the onlooker an impulse to react with the hands (98\% of positive responses).

\section{Procedure}

The participants were tested individually in a soundattenuated Faraday room during a single experimental session lasting approximately $40 \mathrm{~min}$ and consisting of two blocks (upper limb, lower limb). Each participant was directed to sit in a slightly raised armchair with his or her legs comfortably stretched, the right hand positioned on an arm support, and the head positioned on a fixed head rest. Each was instructed to remain as still and relaxed as possible and to watch the four video clips that were presented on a 19-in. monitor (resolution = $1280 \times 1024$ pixels, refresh frequency $=75 \mathrm{~Hz}$, background luminance of $0.5 \mathrm{~cd} / \mathrm{m}^{2}$ ) set at eye level (the eye-screen distance was $80 \mathrm{~cm}$ ). To ensure that the participants paid attention to the contents of the video clips, they were told that they would be questioned at the end of the session about the visual stimuli presented. TMSinduced MEPs were acquired from the participant's right opponens pollicis (OP) and quadriceps femoris (QF) muscles. Upper and lower limb activity was recorded in separate blocks to precisely identify the optimal scalp locations (OSP) for stimulating each muscle and avoid loss of modulation involving the less stimulated muscle. The order in which the two blocks were presented was counterbalanced across the participants. A single TMS pulse was released during each video presentation at one of two specific time points: (i) during the frame showing the player's foot making contact with the ball $\left(\mathrm{T}_{1}, 1350 \mathrm{msec}\right)$ and (ii) during the frame showing the highest peak of the ball's trajectory $\left(\mathrm{T}_{2}, 1750 \mathrm{msec}\right)$. The same timing was applied to all of the control conditions. The first time point $\left(\mathrm{T}_{1}\right)$ was chosen to evaluate the motor resonant response. As recently demonstrated by Lago and Fernandez-del-Olmo (2011), an unspecific motor activation was found in the hand muscles of participants observing an effector before it made contact with an object. When the effector-object interaction was 
instead shown, the motor program activated via action observation was muscle specific. The second time point $\left(T_{2}\right)$ was set at the highest peak of the ball's trajectory before it disappeared as we intended to maximize the complementary reaction to the stimulus. The order of the videos and the two different TMS delays were randomized within each of the two blocks. One hundred sixty MEPs $(2$ muscles $\times 4$ conditions $\times 10$ repetitions $\times$ 2 time points) were recorded for each participant. Before presenting the videos, each participant's baseline was assessed by acquiring 10 MEPs per block while they passively watched a white-colored fixation cross $(10 \times$ $10 \mathrm{~mm}$ ) on a black background on the computer screen. Ten more MEPs were recorded at the end of each block. By comparing MEP amplitudes recorded during the two baseline series, it was possible to check for any CS excitability changes related to TMS per se in each block. The average amplitude of the two series was then utilized to set each participant's individual baseline for data normalization procedure. An interpulse interval lasting $10 \mathrm{sec}$ was presented between trials to minimize the potential risk of carryover effect of a TMS pulse on the subsequent one. During the first $5 \mathrm{sec}$ of the rest period, a message reminding the participants to keep their hands and legs still and fully relaxed appeared on the screen. Stimuli presentation, EMG recordings, and timing of TMS stimulation were managed by E-Prime V2.0 software (Psychology Software Tools, Pittsburgh, PA) running on a PC.

\section{Data Recording}

\section{TMS}

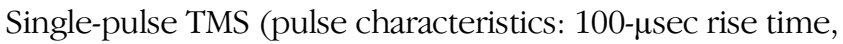
1-msec duration) was delivered using a $70-\mathrm{mm}$ figure-ofeight coil (Magstim polyurethane-coated coil) connected to a Magstim BiStim ${ }^{2}$ stimulator (The Magstim Company, Carmarthenshire, UK). Pulses were delivered to the left M1 corresponding to the hand and leg regions during the "upper limb" and "lower limb" blocks, respectively. The coil was placed tangentially on the scalp, with the handle pointing laterally and caudally (Brasil-Neto et al., 1992; Mills, Boniface, \& Schubert, 1992). The OSP was determined by moving the intersection of the coil in approximately $0.5-\mathrm{cm}$ steps around the target area until a position was reached at which a maximal MEP amplitude was produced in each target muscle with a minimal stimulation intensity. This position was marked on a tight-fitting cap that each participant was asked to wear. During the experimental sessions, the coil was held by a tripod with an articulated arm. The position and orientation of the coil over the OSP was recorded and loaded into the Brainsight 2.0 neuronavigation system (Rogue Research, Montreal, QC, Canada) to maintain accurate placement of the coil throughout the experiment. Defined as the minimum stimulation intensity on the OSP that induced reliable MEPs $(\geq 50-\mu \mathrm{V}$ peak-to-peak amplitude) in a relaxed muscle in 5 of 10 consecutive trials, the resting motor threshold (rMT) was determined for each participant. rMT ranged from $30 \%$ to $62 \%$ (mean $=49.2 \%, S D=6 \%$ ) of the maximum stimulator output in the upper limb block and from 54\% to 78\% (mean $=64.7 \%, S D=7.2 \%$ ) in the lower limb one. Stimulation intensity was set at $120 \%$ of the rMT to record a clear and stable EMG signal.

\section{Electromyography}

MEPs were recorded from the OP muscle of the right hand and from the QF of the right leg. EMG activity was recorded through pairs of surface $\mathrm{Ag}-\mathrm{AgCl}$ cup electrodes (9-mm diameter) placed in a belly-tendon montage. The ground electrode was placed over the dorsal part of the wrist during the upper limb block and over the patella of the leg during the lower limb block. The skin impedance condition, evaluated at rest before beginning the experimental session, was considered of good quality when below the threshold level $(5 \mathrm{k} \Omega)$. Electrodes were connected to an isolable portable ExG input box linked to the main EMG digital amplifier for signal transmission via a twin fiber optic cable (Professional BrainAmp ExG $\mathrm{MR})$. The raw myographic signals were band-pass filtered (20 Hz-1 kHz), amplified before being digitalized (5-KHz sampling rate), and stored on a computer for off-line analysis. EMG data were recorded for a 300-msec interval. The interval was time locked to the delivery of the magnetic stimulation pulse and began $100 \mathrm{msec}$ before the onset of stimulation and ended $200 \mathrm{msec}$ after stimulation. Trials in which any EMG activity was present in the time window preceding the TMS pulse were discarded to prevent contamination of MEP measurements by background EMG activity.

\section{Data Analysis}

The CS excitability of OP and QF muscles was quantified at each stimulation point during each experimental condition by the MEP peak-to-peak amplitude (mV). Those amplitudes deviating more than $3 S D$ s from the mean and the trials contaminated by muscular preactivation were excluded as outliers $(<5 \%)$. A paired-sample $t$ test (two-tailed) was used to compare the amplitude of MEPs recorded during the two baseline trials carried out at the beginning and end of each block. Ratios were computed using the participants' individual mean MEP amplitude recorded during the two fixation-cross periods as baseline (MEP ratio = MEP obtained / MEP baseline). We entered the MEP ratios in a repeated-measures ANOVA with Muscle (OP, QF), Type of action (central kick, lateral kick, mimicked kick, ball), and Stimulation time $\left(\mathrm{T}_{1}, \mathrm{~T}_{2}\right)$ as within-subject factors. The sphericity of the data was verified before performing statistical analysis (Mauchly's test, $p>.05)$. Post hoc pairwise comparisons were carried out using $t$ tests, and Bonferroni correction was applied to 
control $p$ values for multiple comparisons. A significance threshold of $p<.05$ was set for all statistical analyses run in IBM SPSS Statistics 21.0 (Armonk, NY).

\section{RESULTS}

The mean raw MEP amplitudes recorded for each participant during the preexperimental and postexperimental sessions were not significantly different for the $\mathrm{OP}(1.127 \pm 0.716$ vs. $1.013 \pm 0.589 \mathrm{mV}$, respectively; $t(29)=1.42, p=.17)$ or $\mathrm{QF}(0.185 \pm 0.092$ vs. $0.186 \pm$ $0.089 \mathrm{mV}$, respectively; $t(29)=0.04, p=.97$ ) muscles. It can be concluded, therefore, that TMS per se induced no changes in CS excitability during the experiment and that modulation of EMG activity was linked exclusively to the different experimental conditions. The ANOVA on normalized MEP amplitudes showed a statistically significant main effect of Time $\left(F(1,29)=7.21, p<.01, \eta_{p}^{2}=\right.$ $0.20)$, a two-way interaction of Muscle $\times$ Time $(F(1,29)=$ 4.26, $\left.p<.05, \eta_{p}^{2}=0.13\right)$, and a three-way interaction of Muscle $\times$ Type of action $\times$ Time $(F(3,87)=7.27, p<.01$, $\left.\eta_{p}^{2}=0.20\right)$. The results obtained from the post hoc contrasts exploring the source of the significant threeway interaction are outlined as follows.

\section{Motor Resonance in Lower Limb Muscles}

In terms of congruent motor activation, watching the player making contact with the ball elicited a higher activity in the participants' lower limbs at the beginning of the video $\left(\mathrm{T}_{1}\right)$ with respect to the end $\left(\mathrm{T}_{2}\right)$ in the "central," "lateral," and "mimicked" kick conditions ( $p$ s < .05; Figure 2A). This decrease did not occur for the "ball" condition $(p>.05)$, in which a stable activity was found across time points. Notably, the statistically significant decrease in the central, lateral, and mimicked kick conditions at $\mathrm{T}_{2}$ was confirmed when compared with the ball condition $(p s<.05$, Figure $2 \mathrm{~A}$ ), thus suggesting an in- hibitory process leading to a dynamic reduction in CS excitability.

\section{Complementary Motor Activation in Upper Limb Muscles}

The mean MEP amplitude of the OP muscle was higher at $\mathrm{T}_{2}$ than at $\mathrm{T}_{1}$ only for the central kick condition $(p<.05$; Figure $2 \mathrm{~B}$ ). Post hoc comparisons at $\mathrm{T}_{2}$ confirmed this increased activation with respect to the lateral and mimicked conditions ( $p$ s $<.05$; Figure $2 \mathrm{~B}$ ). A significant motor activation in the observer's hand muscle was also found when observing the soccer ball alone in penalty area with respect to the lateral and mimicked conditions $(p<.05$; Figure 2B). This seems to suggest that complementary motor activations are likely linked to object affordance and suitable actions, rather than being a simple by-product of motor imagery (as it might have occurred in the mimicked condition).

\section{Interaction between Motor Resonance and Complementary Motor Activation}

Interestingly, post hoc analyses for the central kick condition showed a statistically significant increase in the leg muscle at the time of contact $\left(\mathrm{T}_{1}\right)$ compared with the hand muscle $(p<.05$; Figure 3$)$, followed by a larger increase in the hand muscle when the ball approached the viewer $\left(\mathrm{T}_{2}\right)$ compared with the leg muscle $(p<$ .05 ; Figure 3).

\section{DISCUSSION}

This study examined the modulation of CS excitability during action observation priming for both congruent and incongruent motor responses at the level of multiple effectors. Our experimental findings show an interesting dissociation: an increase in the leg muscle at the time of

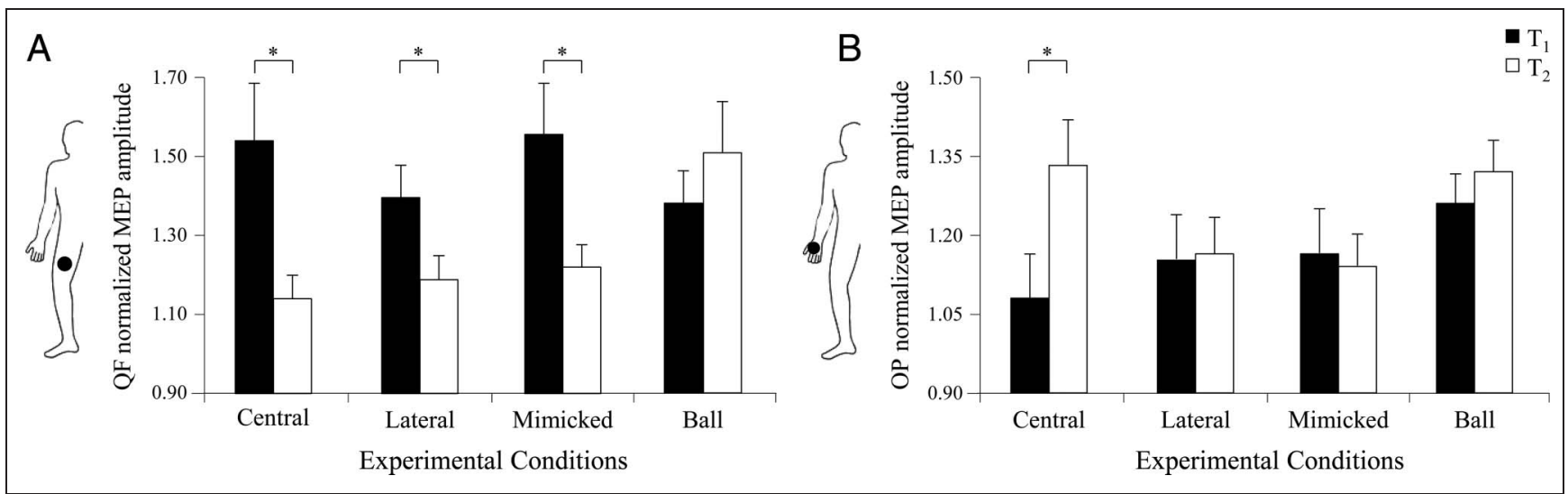

Figure 2. CS activation during observation of a central, lateral, and mimicked kick and of a ball in penalty area. The graph represents the means of the normalized MEP amplitudes recorded from the QF (A) and OP (B) at $\mathrm{T}_{1}$ and $\mathrm{T}_{2}$. Error bars indicate SEMs. Asterisks indicate statistically significant comparisons across TMS time points $(p<.05)$. 


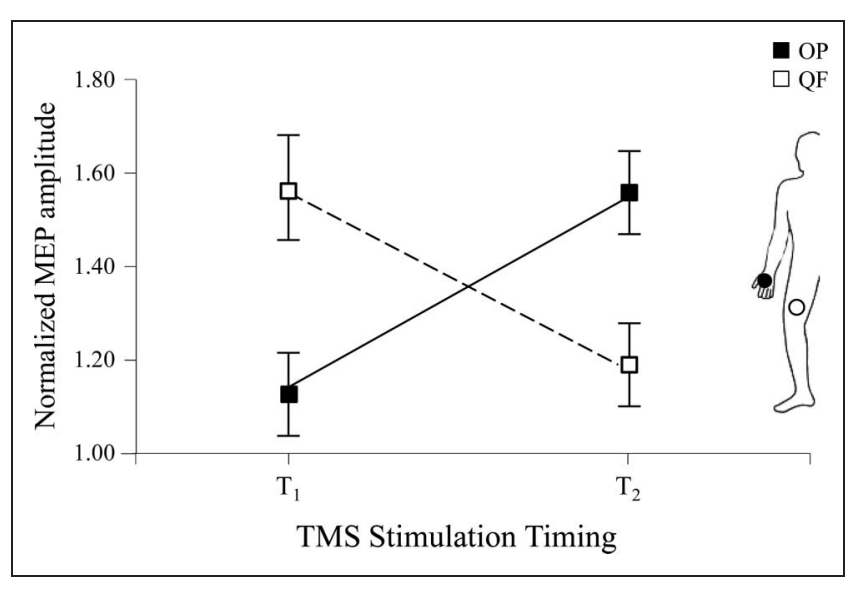

Figure 3. Interplay between normalized MEP amplitudes recorded from the OP and QF at $\mathrm{T}_{1}$ and $\mathrm{T}_{2}$ for the "central" kick condition. Error bars indicate SEMs. Notably, seeing the soccer player kicking the ball at $\mathrm{T}_{1}$ triggered a statistically significant motor facilitation in the observer's lower limb muscles (QF) as compared with the upper limb (OP) muscles, whereas seeing the ball approaching the observer at $\mathrm{T}_{2}$ elicited a statistically significant motor facilitation in the upper limb muscle (OP) as compared with the lower limb (QF) muscle.

contact, followed by an increase in the hand muscle when the ball approaches the viewer.

The study's findings seem to delineate a sophisticated mechanism that is able to dynamically modulate the observer's motor reactions at the level of different limbs over the course of the action and as a function of their relevance given different contexts. Producing an internal replica of the observed action is only useful during the first part of the action sequence, while the observed action unfolds. On the other hand, activating the upper limbs is only useful at $T_{2}$, when preparing for a potential interaction. According to the theoretical framework proposed by Chinellato and colleagues (2013), a two-level competition is at the basis of the mechanism for choosing the most suitable responses to an observed action. In the present paradigm, it is necessary not only to activate the motor pattern that matches the observed action (e.g., kicking the ball) and the one that constitutes the appropriate complementary response (e.g., blocking the ball) but also to decide whether either or both should be simultaneously executed (in the above example, kicking should be inhibited to avoid affecting the quality of the blocking response). As the complexity of movement increases, greater CS modulation may be required to uncouple the two limbs, to prevent unwanted mirror movements (Verstynen \& Ivry, 2011).

Notably, in the ball condition, a stable motor activation was present across time points. The presence of the ball in the penalty area and the salient affordances about what one could do in this situation (i.e., kick it, but also use our hands for throw-ins) likely evoked a readiness to enact them, which is a disposition to engage in meaningful situations (Di Paolo \& De Jaegher, 2012).

In neural terms, this pattern of results might be because of an activation of the canonical neuron networks.
This type of neuron responds not only during the execution of a specific type of action but also during the perception of the objects that are related to this particular action (Rizzolatti \& Craighero, 2004). For instance, canonical motor neurons that become active during precision grip movements become also active upon presentation of a small object graspable by a precision grip (Murata et al., 1997). On the contrary, it might well be that the modulation of motor pathways excitability found in participant's lower limbs while observing a mimicked kick was the product of the activation of classical mirror neurons. The role of the human mirror neuron system has long been debated in the light of different interpretations focusing on its comprehension purposes (i.e., extracting the goals underlying observed actions; Rizzolatti \& Sinigaglia, 2010) or on its predictive aspects (Kilner, 2011).

In a recent stimulating review, Hamilton (2013) suggests a third perspective: the social responding hypothesis. In her view, the main purpose of the mirror neuron system would be "to respond, in real-time and in a socially appropriate fashion, to the actions of others" (Hamilton, 2013). Alternatively, the idea of an associative memory able to implement mirroring behavior and adapt through experience to generate complementary responses would also explain our results: The existence of counter-mirror effects might support this hypothesis (Barchiesi \& Cattaneo, 2013; Cavallo, Heyes, Becchio, Bird, \& Catmur, 2013; Catmur, Walsh, \& Heyes, 2007).

In conclusion, the findings presented here take research on the action observation system a step further by showing that the observation of a pure biological movement (i.e., "mimicked" kick condition) is sufficient to produce motor resonance and that an interplay of congruent and incongruent CS activations at the level of multiple effectors might occur, depending on the context.

An aspect that must be emphasized is that the participants in our experiments were not given instructions, which could have created a bias to mentally matching (or not) the observed action, or asked to perform tasks not associated with meaningful behavior in real life. We firmly support the adoption of paradigms that are likely to uncover spontaneous tendencies rather than dispositions formed during the execution of the experimental task itself. Future studies in ecological contexts are needed to assess whether the complementary motor response is generated as a product of a parallel, visually derived associative process.

\section{Acknowledgments}

This work was supported by grant 287713 of the FP7: REWIRE project and the Progetto Strategico, Università di Padova (N. 2010XPMFW4) to U. C.

Reprint requests should be sent to Luisa Sartori, Dipartimento di Psicologia Generale, Università di Padova, Via Venezia 8, 35131, Padova, Italy, or via e-mail: luisa.sartori@unipd.it. 


\section{REFERENCES}

Abernethy, B., Zawi, K., \& Jackson, R. C. (2008). Expertise and attunement to kinematic constraints. Perception, 37, 931-948.

Aglioti, S. M., Cesari, P., Romani, M., \& Urgesi, C. (2008). Action anticipation and motor resonance in elite basketball players. Nature Neuroscience, 11, 1109-1116.

Alaerts, K., Heremans, E., Swinnen, S. P., \& Wenderoth, N. (2009). How are observed actions mapped to the observer's motor system? Influence of posture and perspective. Neuropsychologia, 47, 415-422.

Avenanti, A., Bolognini, N., Malavita, A., \& Aglioti, S. M. (2007). Somatic and motor components of action simulation. Current Biology, 17, 2129-2135.

Barchiesi, G., \& Cattaneo, L. (2013). Early and late motor responses to action observation. Social Cognitive and Affective Neuroscience, 8, 711-719.

Borroni, P., \& Baldissera, F. (2008). Activation of motor pathways during observation and execution of hand movements. Social Neuroscience, 3, 276-288.

Borroni, P., Montagna, M., Cerri, G., \& Baldissera, F. (2005). Cyclic time course of motor excitability modulation during the observation of a cyclic hand movement. Brain Research, 1065, 115-124.

Brasil-Neto, J. P., Cohen, L. G., Panizza, M., Nilsson, J., Roth, B. J., \& Hallett, M. (1992). Optimal focal transcranial magnetic activation of the human motor cortex: Effects of coil orientation, shape of the induced current pulse, and stimulus intensity. Journal of Clinical Neurophysiology, 9, 132-136.

Briggs, C. G., \& Nebes, R. D. (1975). Patterns of hand preference in a student population. Cortex, 11, 230-238.

Catmur, C., Walsh, V., \& Heyes, C. (2007). Sensorimotor learning configures the human mirror system. Current Biology, 17, 1527-1531.

Cavallo, A., Heyes, C., Becchio, C., Bird, G., \& Catmur, C. (2013). Timecourse of mirror and counter-mirror effects measured with transcranial magnetic stimulation. Social Cognitive and Affective Neuroscience, 9, 1082-1088.

Chinellato, E., Ognibene, D., Sartori, L., \& Demiris, Y. (2013). Time to change: deciding when to switch action plans during a social interaction. In N. Lepora, A. Mura, H. Krapp, P. Verschure, \& T. Prescott (Eds.), Biomimetic and Biobybrid Systems (pp. 47-58). Berlin, Heidelberg: Springer.

Craighero, L., Fadiga, L., Rizzolatti, G., \& Umiltà, C. (1998). Visuomotor priming. Visual Cognition, 5, 109-125.

Di Paolo, E., \& De Jaegher, H. (2012). The interactive brain hypothesis. Frontiers in Human Neuroscience, 6, 1-16.

Di Pellegrino, G., Fadiga, L., Fogassi, L., Gallese, V., \& Rizzolatti, G. (1992). Understanding motor events: A neurophysiological study. Experimental Brain Research, 91, 176-180.

Fabbri-Destro, M., \& Rizzolatti, G. (2008). Mirror neurons and mirror systems in monkeys and humans. Physiology, 23, 171-179.

Fadiga, L., Craighero, L., \& Olivier, E. (2005). Human motor cortex excitability during the perception of others' action. Current Opinion in Neurobiology, 15, 213-218.

Fadiga, L., Fogassi, L., Pavesi, G., \& Rizzolatti, G. (1995). Motor facilitation during action observation: A magnetic stimulation study. Journal of Neurophysiology, 73, 2608-2611.

Flach, R., Press, C., Badet, A., \& Heyes, C. M. (2010). Shaking hands: Priming by social effects. British Journal of Psychology, 101, 739-749.

Gallese, V., Fadiga, L., Fogassi, L., \& Rizzolatti, G. (1996). Action recognition in the premotor cortex. Brain, 119, 593-610.

Gangitano, M., Mottaghy, F. M., \& Pascual-Leone, A. (2001). Phase-specific modulation of cortical motor output during movement observation. NeuroReport, 12, 1489-1492.
Gibson, J. J. (1979). The ecological approach to visual perception. Boston: Houghton Mifflin.

Giorello, G., \& Sinigaglia, C. (2007). Perception in action. Acta Biomedica, 78, 49-57.

Hamilton, A. F. (2013). The mirror neuron system contributes to social responding. Cortex, 49, 2957-2959.

Janssen, L., Steenbergen, B., \& Carson, R. G. (2013). Anticipatory planning reveals segmentation of cortical motor output during action observation. Cerebral Cortex, 25, 192-201.

Jeannerod, M. (1994). The representing brain: Neural correlates of motor intention and imagery. Behavioral and Brain Sciences, 17, 187-245.

Keysers, C. (2009). Mirror neurons. Current Biology, 19, R971-R973.

Kilner, J. M. (2011). More than one pathway to action understanding. Trends in Cognitive Sciences, 15, 352-357.

Kilner, J. M., Vargas, C., Duval, S., Blakemore, S. J., \& Sirigu, A. (2004). Motor activation prior to observation of a predicted movement. Nature Neuroscience, 12, 1299-1301.

Knoblich, G., Butterfill, S., \& Sebanz, N. (2011). Psychological research on joint action: Theory and data. In B. Ross (Ed.), The psychology of learning and motivation (pp. 59-101). Burlington, VT: Academic Press.

Lago, A., \& Fernandez-del-Olmo, M. (2011). Movement observation specifies motor programs activated by the action observed objective. Neuroscience Letters, 493, 102-106.

Makris, S., \& Urgesi, C. (2014). Neural underpinnings of superior action prediction abilities in soccer players. Social Cognitive and Affective Neuroscience, 10, 342-351.

Mills, K. R., Boniface, S. J., \& Schubert, M. (1992). Magnetic brain stimulation with a double coil: The importance of coil orientation. Electroencephalography and Clinical Neurophysiology, 85, 17-21.

Molenberghs, P., Cunnington, R., \& Mattingley, J. B. (2012). Brain regions with mirror properties: A meta-analysis of 125 human fMRI studies. Neuroscience and Biobehavioral Reviews, 36, 341-349.

Montagna, M., Cerri, G., Borroni, P., \& Baldissera, F. (2005). Excitability changes in human corticospinale projections to muscles moving hand and fingers while viewing a reaching and grasping action. European Journal of Neuroscience, 22, 1513-1520.

Mukamel, R., Ekstrom, A. D., Kaplan, J., Iacoboni, M., \& Fried, I. (2010). Single-neuron responses in humans during execution and observation of actions. Current Biology, 20, 750-756.

Murata, A., Fadiga, L., Fogassi, L., Gallese, V., Raos, V., \& Rizzolatti, G. (1997). Object representation in the ventral premotor cortex (area F5) of the monkey. Journal of Neurophysiology, 78, 2226-2230.

Newman-Norlund, R. D., Noordzij, M. L., Meulenbroek, R. G., \& Bekkering, H. (2007). Exploring the brain basis of joint action: Co-ordination of actions, goals and intentions. Social Neuroscience, 2, 48-65.

Ocampo, B., \& Kritikos, A. (2010). Placing actions in context: Motor facilitation following observation of identical and nonidentical manual acts. Experimental Brain Research, 201, 743-751.

Ocampo, B., Kritikos, A., \& Cunnington, R. (2011). How frontoparietal brain regions mediate imitative and complementary actions: An fMRI study. PLoS One, 6, e26945.

Rizzolatti, G., \& Craighero, L. (2004). The mirror-neuron system. Annual Review of Neuroscience, 27, 169-192.

Rizzolatti, G., \& Sinigaglia, C. (2010). The functional role of the parieto-frontal mirror circuit: Interpretations and misinterpretations. Nature Reviews Neuroscience, 11, 264-274. 
Rossi, S., Hallett, M., Rossini, P. M., Pascual-Leone, A., \& Safety of TMS Consensus Group. (2009). Safety, ethical considerations, and application guidelines for the use of transcranial magnetic stimulation in clinical practice and research. Clinical Neurophysiology, 120, 2008-2039.

Sartori, L., Becchio, C., Bulgheroni, M., \& Castiello, U. (2009). Modulation of the action control system by social intention: Unexpected social requests override preplanned action. Journal of Experimental Psychology: Human Perception and Performance, 35, 1490-1500.

Sartori, L., Betti, S., \& Castiello, U. (2013a). Modulation of corticospinal excitability during action observation. Journal of Visualized Experiments, 82, e51001.

Sartori, L., Betti, S., \& Castiello, U. (2013b). When mirroring is not enough: That is, when only a complementary action will do (the trick). NeuroReport, 24, 601-604.

Sartori, L., Betti, S., Chinellato, E., \& Castiello, U. (2015). The multiform motor cortical output: Kinematic, predictive and response coding. Cortex. doi:10.1016/j.cortex.2015.01.019. [Epub ahead of print]

Sartori, L., Bucchioni, G., \& Castiello, U. (2012). Motor cortex excitability is tightly coupled to observed movements. Neuropsychologia, 50, 2341-2347.

Sartori, L., Bucchioni, G., \& Castiello, U. (2013). When emulation becomes reciprocity. Social Cognitive and Affective Neuroscience, 8, 662-669.

Sartori, L., Cavallo, A., Bucchioni, G., \& Castiello, U. (2011). Corticospinal excitability is specifically modulated by the social dimension of observed actions. Experimental Brain Research, 211, 557-568.

Sartori, L., Cavallo, A., Bucchioni, G., \& Castiello, U. (2012). From simulation to reciprocity: The case of complementary actions. Social Neuroscience, 7, 146-158.

Sebanz, N., Bekkering, H., \& Knoblich, G. (2006). Joint action: Bodies and minds moving together. Trends in Cognitive Sciences, 10, 70-76.

Strafella, A. P., \& Paus, T. (2000). Modulation of cortical excitability during action observation: A transcranial magnetic stimulation study. NeuroReport, 11, 2289-2292.

Tomeo, E., Cesari, P., Aglioti, S. M., \& Urgesi, C. (2013). Fooling the kickers but not the goalkeepers: Behavioral and neurophysiological correlates of fake action detection in soccer. Cerebral Cortex, 23, 2765-2778.

Tucker, M., \& Ellis, R. (1998). On the relations between seen objects and components of potential actions. Journal of Experimental Psychology: Human Perception and Performance, 24, 830-846.

Turella, L., Tubaldi, F., Erb, M., Grodd, W., \& Castiello, U. (2012). Object presence modulates activity within the somatosensory component of the action observation network. Cerebral Cortex, 22, 668-679.

Urgesi, C., Candidi, M., Fabbro, F., Romani, M., \& Aglioti, S. M. (2006). Motor facilitation during action observation: Topographic mapping of the target muscle and influence of the onlooker's posture. The European Journal of Neuroscience, 23, 2522-2530.

Urgesi, C., Maieron, M., Avenanti, A., Tidoni, E., Fabbro, F., \& Aglioti, S. M. (2010). Simulating the future of actions in the human corticospinal system. Cerebral Cortex, 20, 2511-2521.

Urgesi, C., Savonitto, M. M., Fabbro, F., \& Aglioti, S. M. (2012). Long- and short-term plastic modeling of action prediction abilities in volleyball. Psychological Research, 76, 542-560.

van Schie, H. T., van Waterschoot, B. M., \& Bekkering, H. (2008). Understanding action beyond imitation: Reversed compatibility effects of action observation in imitation and joint action. Journal of Experimental Psychology: Human Perception and Performance, 34, 1493-1500.

Verstynen, T., \& Ivry, R. B. (2011). Network dynamics mediating ipsilateral motor cortex activity during unimanual actions. Journal of Cognitive Neuroscience, 23, 2468-2480.

Wassermann, E. M. (1998). Risk and safety of repetitive transcranial magnetic stimulation: Report and suggested guidelines from the International Workshop on the Safety of Repetitive Transcranial Magnetic Stimulation, June 5-7, 1996. Electroencephalography and Clinical Neurophysiology-Evoked Potentials Section, 108, 1-16.

Weissensteiner, J., Abernethy, B., Farrow, D., \& Müller, S. (2008). The development of anticipation: A cross-sectional examination of the practice experiences contributing to skill in cricket batting. Journal of Sport E Exercise Psychology, 30, 663-684. 